\title{
Contemporary Plastic Visions of Glass Formation Arts to Enrich the Aesthetic and Creative Side upon the Students of Art Education at the University of Umm Al Qura- Saudi Arabia
}

\author{
Mona Ibrahim Hussein, Sanaa Mohamed Rashad Similan* \\ Department of Art Education, Faculty of Education Umm Al Qura University, Makkah, Saudi Arabia \\ *Corresponding author: Dr.Sanaa-mrs@hotmail.com
}

Received April 29, 2015; Revised May 10, 2015; Accepted May 21, 2015

\begin{abstract}
Through history the way of blowing in the glass had a special position in the production of bottles and vases of decorations, this method, which relies on air mobilization inside the vials and templates after heated and melted at high degrees of heat as the blowing process in a block of dough glass produces different forms of glass products such as jugs, vases, candy boxes, decoration boxes, flasks, and the artist identifies the form and the final size of the piece to be configured, and choose the decoration and etching type on the surface, and needs high technical skills such as assiduity in front of furnaces operating at high degrees of heat, and continuous training to master this industry, as well as providing creative and artistic ability to acquire more skill and then convoying time to keep up with innovation, development and production of various models from time to time. This research provides a modern entrances in teaching stained glass course at the Faculty of Education - Umm Al Qura University with plastic contemporary visions, so the educational and service institutions can benefit from the development of the artwork, in an effort to reach the highest degree of excellence in performance, and through the production of innovative art works in glass art, in order to identify the theoretical concepts related to the work of colored and stained glass to study the techniques and technical, aesthetic and utilitarian characteristics of glass and their applications.
\end{abstract}

Keywords: glass, colors, raw material, creative thinking, experiment, research

Cite This Article: Mona Ibrahim Hussein, and Sanaa Mohamed Rashad Similan, "Contemporary Plastic Visions of Glass Formation Arts to Enrich the Aesthetic and Creative Side upon the Students of Art Education at the University of Umm Al Qura- Saudi Arabia.” American Journal of Educational Research, vol. 3, no. 6 (2015): 713-720. doi: 10.12691/education-3-6-8.

\section{Introduction}

Glass is one of the oldest materials used by the ancient forefathers, and can be considered of the volcanic materials which had been formed willingly in nature, and this type of glass is called (Obsidian volcanic glass).Chemically, glass is known as the steel resulting from the union or the interaction of inorganic non-volatile metal oxides resulting from the disintegration of some salts of alkaline elements, and the elements of alkaline dusts and their interaction with pure sand to be some sort of irregularly metal silicates, copper (2007). We note that the crystalline form is advanced in that glass, where we find that most types consist of sand, limestone, soda ash, and sand which is of pure or quartz type, known chemically as the silicon dioxide SiO2. In the sand every atom Silicon is associated with four oxygen atoms covalently with completely regular crystallization, but physically we know the glass as a liquid cooled to the point led to the loss of crystalline form, and has a high viscosity preventing its formation in the form of crystals, and the glass industry has developed in the world and it was much used in various purposes, copper (1995). The arts of forming glass have several techniques (thermal, mechanical, chemical), and the Ancient Egyptians are the first to laid the foundations of some of the methods of formation of the glass thermally, as evidenced by the various antiquities, which illustrate that the technical configuration character is featuring the structural installation linked to properties in the arts of sculpture and photography. The twentieth century has witnessed in most countries of the world technical and scientific development sophisticated in reshaping the glass methods thermally so as to achieve the aesthetics of artistic composition and employing it in various fields, and in the modern era, glass has become an integral part of our daily lives, it almost exists everywhere, whether it is transparent or semitransparent or opaque colored or non-colored.The glass industry of ancient crafts was inherited by generations, generation after generation until this day and age, and it is one of the crafts that is drawing its material 
from the environment, which is depending on the waste glass as a raw material, and the colors chosen by the artist, and this industry has seen a significant and remarkable development in the Islamic Era in the Arab Region, especially in the Levant and the Arab Maghreb countries, Islamic decoration emerged on the surface of the mirrors and bottles with colors of gold-plated and overlapping inscriptions lines and engineering drawings that characterized the Islamic Art, and this art remained in the boom and has gained great importance, and then introduced the modern techniques in glass shapes industry as an alternative to the traditional blowing, because they are tied closely with the decor and accessory products.

\section{Find a Problem}

Research problem is limited in how we can take advantage of the characteristics of the Fine Arts in the glass to put a new entrance to the development of contemporary plastic visions in order to enrich the aesthetic and creative side with the students of art education at the University of Umm Al-Qura?

\section{Imposition of the Research}

The research is supposing that the stained glass arts develop the creative side with the students of the Department of Art Education at the University of Umm Al-Qura, and is increasing the enrichment of vision to create contemporary works of glass art.

\section{Research Objectives:}

The research aims to...

4.1. The disclosure of Fine and technical characteristics of the glass arts and what they are carrying of aesthetic values.

4.2. The development of creative and skill side of the students of Art Education Department at Umm Al Qura University.

4.3. Finding a new approach to the teaching of stained glass course by introducing plastic contemporary vision through the study of arts and technical characteristics of the glass arts and applications.

4.4. The originality and uniqueness, which achieves the aesthetics of creativity that combines fine and functional values.

4.5. The capacity for flexibility and adaptation to the severity of the glass with other supplementary materials.

\section{Importance of the Research}

The importance of research is lying in the following:

5.1. Opening new horizons for the students of arts, about the importance of the formulation of the glass arts with contemporary plastic arts visions.

5.2. The innovation of an entrance to the teaching of glass arts, which are containing multiple plastic and technical aspects.

5.3. The development of creative and innovative capacity among the students of art education - Umm Al Qura University.

\section{The Schedule of the Research}

6.1. The application of research had been experienced to the students of the eighth level, Department of Art Education - Faculty of Education, through a random sample representing $20 \%$ of the total students, or about 25 students, where they were divided into two groups, one based on work on a flat glass, and the other adopted the implementation on plastic strips.

6.2. The use of glass art techniques employed in the production of contemporary art works through the use of: pieces of glass of different sizes and various shapes, strips of transparent plastic, transparent colors, multiple welds from: putty, transparent colloidal material, colored oxides for coloration.

6.3. Showing applied results implementing the two sets of students business for glass arts.

\section{Research Methodology}

The research is following the descriptive approach in the application, by the employment of the descriptive approach to the ores of the glass and their properties and to identify the technical and plastic methods for the use of glass in the implementation of art works, as well as the application of the research experience for students to develop contemporary plastic visions of the arts of glass formation.

\subsection{First, the Theoretical Framework}

Creativity (Creative Definitions):

It also was dealt by Akel (1975):

7.1.1. The Creativity is an integrated unit to a group of self-objective factors that lead to the achievement of new authentic valuable production by the individual and the group.

7.1.2. The Creativity is the mentality of the individual so he can be accessed to new ideas or products, or re-link the ideas of existing products and new innovative way.

7.1.3. The Creativity is the ability to deal comfortably with vague or non-specific ways and the creation of new entrances and workout methods and the applications of entirely new positions.

7.1.4. The Creativity is a new way of solving a problem in a logical manner.

7.1.5. It is a work of mind done by the individual using his abilities to gain access to new ideas or unfamiliar uses.

From the previous display of the different definitions of creativity we can see that the creativity is a human activity of a refined and distinct mind, resulting of the interaction of mental and personal and social factors of the individual, so that this interaction leads to the products of new or innovative solutions to theoretical or applied positions in the field of science or the fields of life, and these areas are characterized by modernity and originality, flexibility and social value.

\subsubsection{Creative Thinking}

The requirements of information age and their rapid and sustained development; leads us to search for different solutions to important problems that are facing us, and the best of these solutions; the creative thinking which helps 
us to face the problems of life and the requirements of modern issues, and that the basic requirements of society necessitates the existence of mental rely on thinking in general and to the Creative thinking in particular.

And creativity is a new revelation of the facts and the events and insights and implications and values existing in life, which in this sense is a case of expanding the knowledge of life around us, and to deal with them intelligently and insight. Creativity is a contemplate, a criticism, an overcome and an anticipate to build a new conceptual, sentimental, and cybernetic world where originality and individuality features are different, but sometimes exceeded the familiar and exit from the traditional patterns, and the creativity is blowing old and new objective factors together represented in the experiences and knowledge charged of humanitarian thought unlimited by time and place.

And creativity does not arise in a vacuum because it depends on two sides. the first is innate or natural or personal readiness and the second is refining this instinct or that readiness, developing and directing them to the appropriate destination, what is meant by innovation and creativity here is to create the appropriate educational site that allows the emergence of the different capacities of individuals at work.

\subsubsection{Creative Thinking Development Factors}

7.1.2.1. Rich cultural and scientific and technical environment It is intended for the family environment to be filled with environmental features that lead the individual to the cognitive experiences accumulated by the individual in the different stages of later life, and this does not negate the exit of creators of non-rich families culturally and scientifically and technically, so that the society compensate the decrease in the family.

7.1.2.2. The nature of social interaction experienced by the individual: social interaction may be counterproductive or development factor, there is an impact to the environment of work or school and work and school colleagues, and social pressures represented in customs and traditions.

7.1.2.3. Motivation: What ismeant here is the individual motivation toward learning, and they are internal engines to move conduct and behavior function toward the achievable goal.

7.1.2.4. Memory stocks: linguistic inventory capacity increases the thought processes and we can get the facts without thinking but we cannot think without facts.

7.1.2.5. The exercise of constructive criticism: if the individual possessed a large stockpile of knowledge and experience, and possess the skills and strategies of thinking and problem solving, he will be able to exercise constructive criticism, and therefore this criticism is directed towards poked to highlight the weaknesses and provide alternatives.

\subsubsection{Definition of Glass Material:}

Glass is known as transparent material, solid, easy to break, resulting from sand smelting with soda or potash and other components, and this is done in special furnaces built of thermal bricks on alumina, and heat melting is between (1350 m - $1500 \mathrm{~m}$ ) Copper (1968). Scientists consider that the glass material of the physical side is the image of the fourth material in Nature, namely, (a glass case) because it combines the qualities and characteristics of the cases of solidity and liquidity according to temperature, so we can call it (liquid under refrigeration) and structural installation of glass does not have a special arrangement for its fractions, and the glass is a shiny material with zero porosity and poorly connected with heat and electricity, Farouk (1995: 62).

\subsubsection{The New in the Physical and Chemical Properties of Glass}

The physical and chemical properties of the glass and features that surpass many other materials, has been known to students of the glass to the modern era, but this era, including contents of the intellectual and scientific evolution, and breaking a lot of well-known laws to us to the beginning of the era of the Industrial Revolution and continuing researches, and studying Modern Sciences, has been possible to put glass material in the first row of the study and analysis and scientific research, and thanks to those researches has been possible to add recipes and many features of the glass material, so the glass became not limited to that it is unbreakable and resistant to heat, but to make some of which are fine in the softness of silk, and make other glasses harsh as steel.

There are also other characteristics of the glass of the Recent Epoch, that the average person does not expect, although the glass has been known since immemorial time as an insulating material for electricity, it has been possible to add items to help it to be a good conductor of electricity, which is a crust of metal oxides does not exceed (1/2) millionths of an inch stuck in the glass, and is connecting the electrical current with the liquidity which is leaded by a wire of copper. Also the flexibility of the glass was added after the formation, so that might make a thin glass bar bearing qualities and properties made with silk ribbon, and also the glass wool, which could isolate the soft fibers of glass softer as satin texture and dander wool when insulation and operating.

\subsection{Second- The Applied Side}

The aim of this part of the research is to the breadth of vision of the students in the creative side through the implementation of applied science through the development of innovative backgrounds of plastic strips or transparent glass thickness of $4 \mathrm{~mm}$, where the students put the colors on those backgrounds and processing by packing glass pieces according to the design prepared in advance, Figure 1, which helped to increase the ability of students to the fluency in the brainstorm and develop new formulations in the field of art of glass composition.

And in some cases the work surface is processing by adding colors on the surface of the water and forming them automatically and pull the color by the glass or plastic slide, and this way have been known (marbling) manner as shown in Figure 2.

Technical work carried out by the students also relied on various technical skills of glass, such as : welding, forming and localization, chipping, assembly, and then put the appropriate seams of the design, whether (paste with colored oxides or welding by a colloidal transparent material, etc.), have also been used metal chains and rings for different forms of confirmation on the line element within the design and the link between the glass and cut each other with transparent colloid to give the required 
flexibility, both in the expression of the folds of clothing or to determine the outline of the shape, Figure 3.

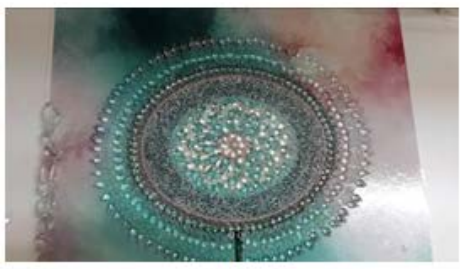

A.

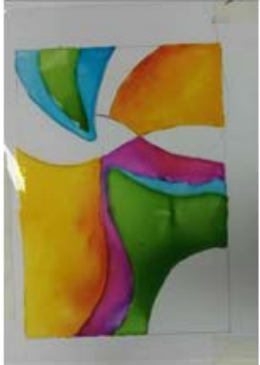

D.

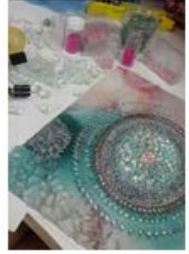

B.

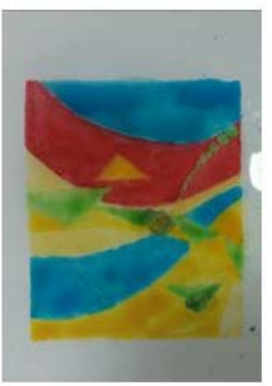

E.

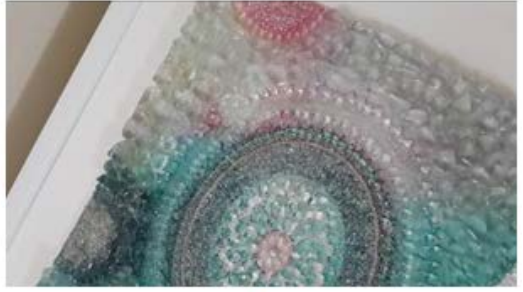

C.

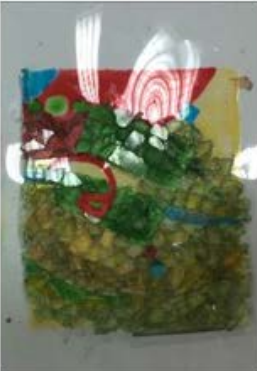

F.

Figure 1. Steps of compaction of glass pieces according to the design prepared in advance

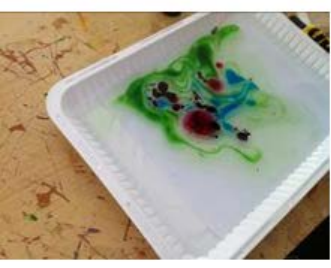

A.

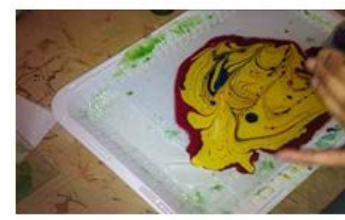

B.

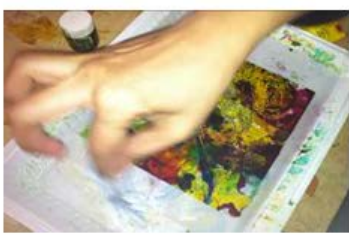

C.

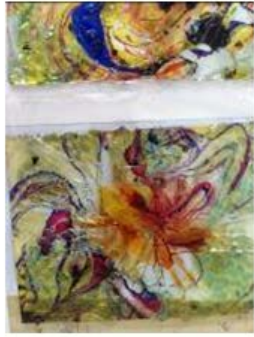

D.

Figure 2. steps of work in (Marbling) way

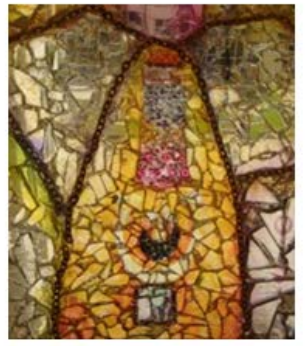

A.

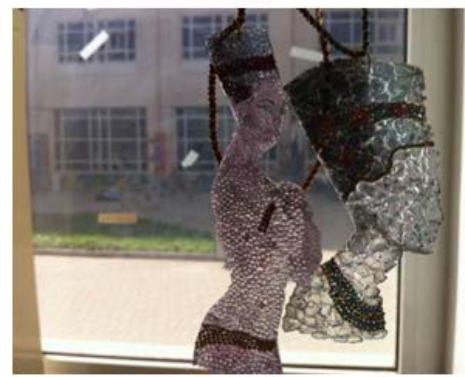

D.

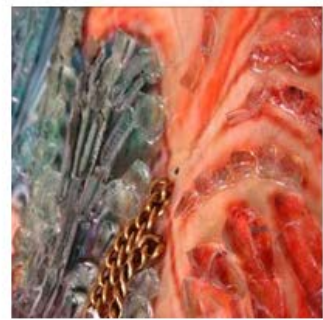

B.

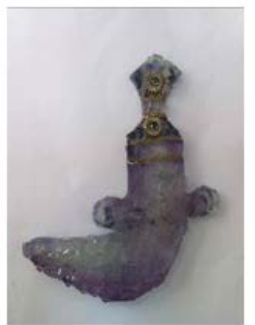

E.

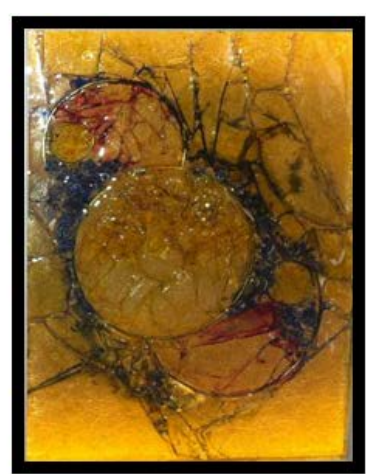

c.

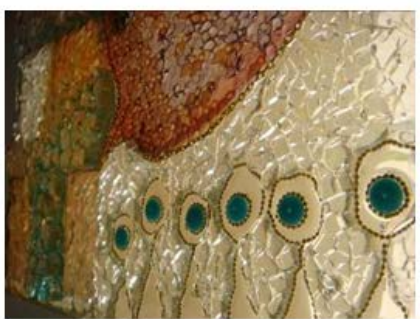

F.

Figure 3. Illustrates the different ways of welds used for thread pieces of glass into artwork

Introducing the element of light has helped to emphasize the transparency of the work of aesthetic art and highlighting the artistic value of the work through the optical color, and the definition of the student on the technical and plastic properties of some raw materials used in glass jewelry, such as molten plastic, glass, stone and lobes, etc., and the diversity came in the thickness of the glass used and different trends of stack them in order to emphasize the design elements and the training of students on the skills required, through the achievement of 
varying heights to show the aesthetic and plastic values of the design and the emphasis on the third dimension of

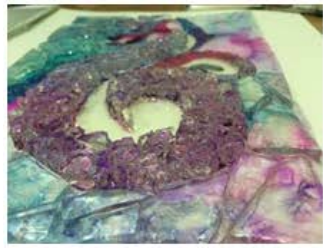

A.

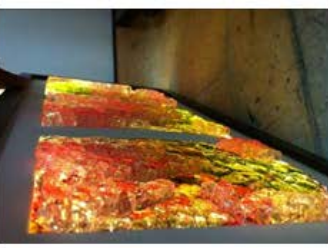

B.

glass artwork, as shown in Figure 4.

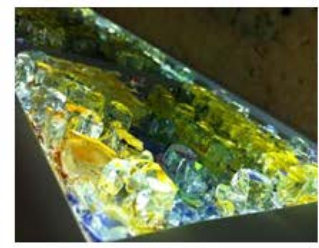

C.

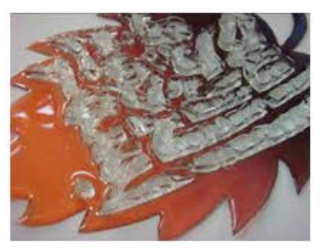

D.

Figure 4. Illustrates the difference in heights in the compaction of the glass pieces to emphasize the intellectual depth of the design

As has been also the implementation of a set of prefabricated templates, Figure 5, and used according to the need of design by pouring a transparent plastic material with transparent color in coded blocks of: (Metal or clay or silicon. etc.).

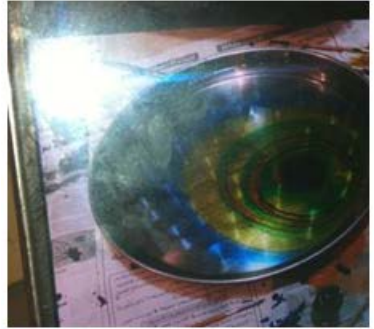

A.

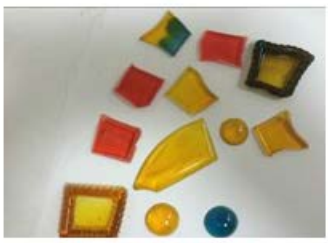

D.

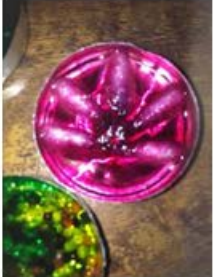

B.

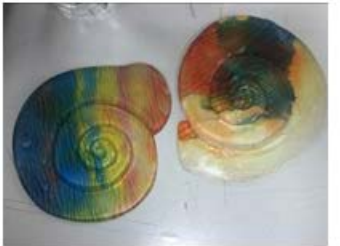

E.
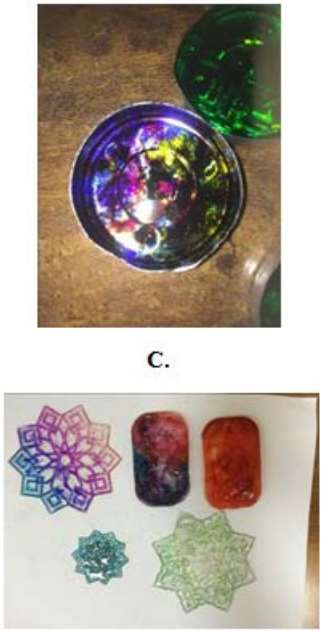

F.

Figure 5. A set of templates prepared and used in the practical application

At this stage the glass artworks produced were rated by the students into two groups:

First: a group of art works based on glass backgrounds.

Second: a group of art works based on the backgrounds of the plastic strips.

The following is an explanation of these groups:

First: A group of art works based on glass backgrounds:
And here is the distribution of the color on the glass surface in two ways, first be according to the pre-design and second by the way of poured color automatically so that the colors merge with each other to give the composition of a color plan consistent with the student creations.

A. Art crafts depending on coloring the design prepared in advance:

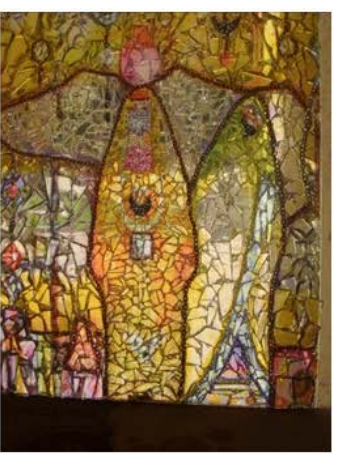

c.

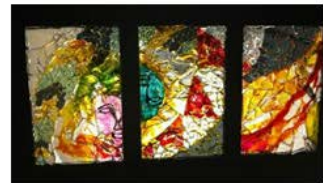

F.

Figure 6. Artworks based on preset design 
(B) Works depending on the coloring of backgrounds and color poured directly on the surface of the work:

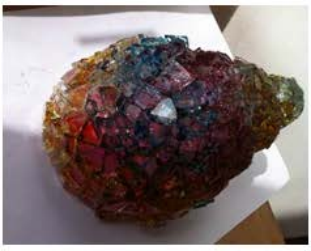

A.

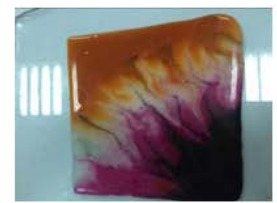

D.
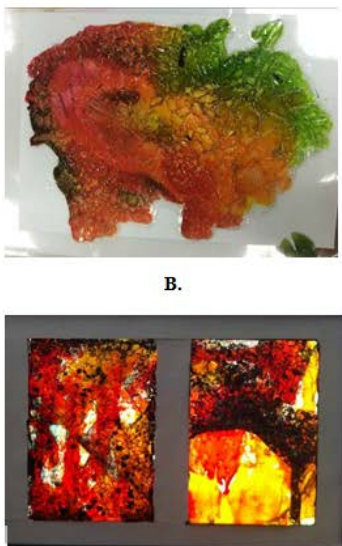

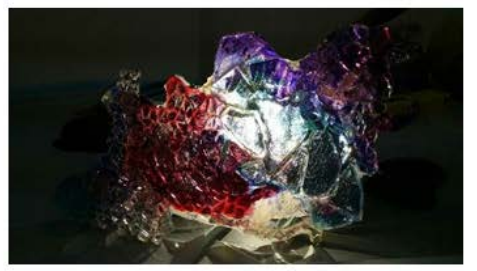

c.

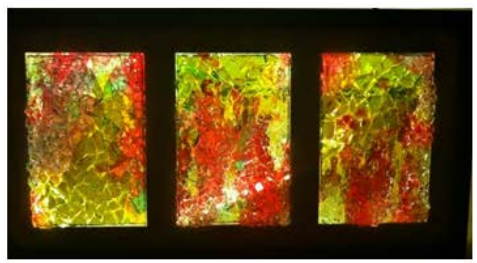

E.

Figure 7. works of art based on direct coloring to the work surface

C - The method of drawing color from above the water surface (style of Marbling):

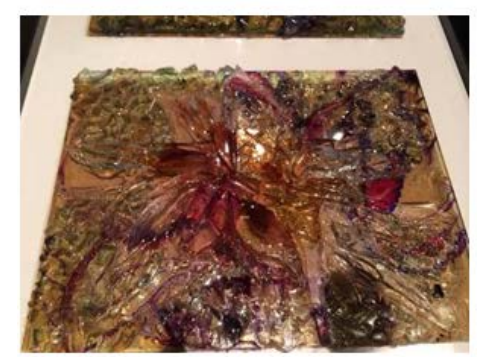

A.

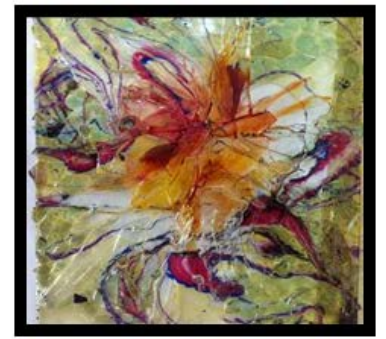

B.

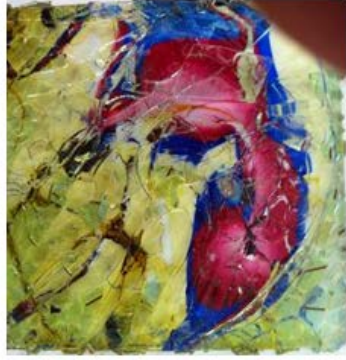

c.

Figure 8. Artworks style of Marbling adopted in the implementation

Second: a group of works of art based on the backgrounds of plastic segments:

And here the design is prepared using computer software and printing the design on plastic slides using printing machines to print colored design on the surface of the plastic slide Figure 9, and then preparing the work surface for the start of installing glass pieces on the desired design details.

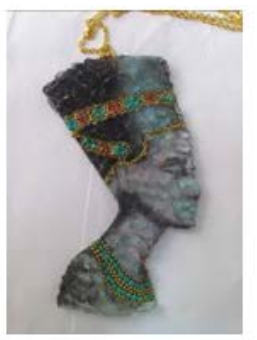

A.

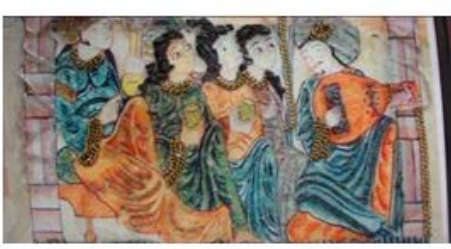

D.

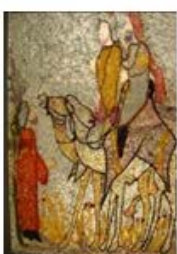

G.

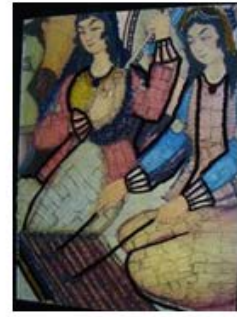

B.

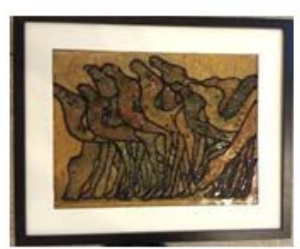

E.

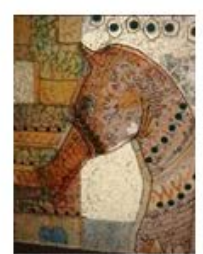

H.

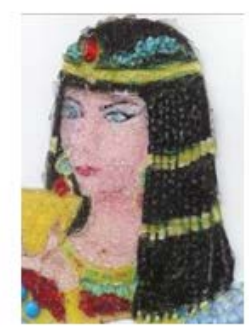

C.

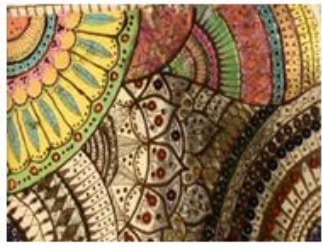

F.

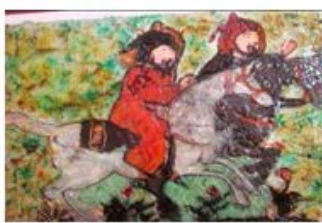

I.

Figure 9. Represents artistic works carried out depending on the backgrounds of plastic strips 


\section{Results of the Applied Experiment of the Research}

From the above presentation of applied experience for the students we concluded:

8.1. The glass with its positive dimensions helps to enrich the creative thinking and innovative for the students.

8.2. The artwork was characterized by diversity in the application and dealing with raw glass in various forms and applications, whether through the achievement of innovation in design, or in the use of various technologies in the artwork.

8.3. Achieving a balance between the data and the used raw materials and modern technology, requires more effort to know the properties of the raw material, as well as add-ons, which leads to change the function of the raw material and the uses of the area and its expressive impact on the user and the receiver.

8.4. The development of creativity among the students to open the horizons of excellence and exclusivity in the field of stained glass.

8.5. Rooting aesthetic values of the subject for our purposes and our needs, and then access to the production of works of art by using glass in a formative manner and innovative visions through attempts and experiments carried out by the students of the Department of Art Education - Umm Al Qura University.

8.6. Artwork integration with practical work both of them complements each other, the applied work enters in artistic production in order to achieve the functional aspect and artwork enters in the industry in order to achieve the touch of creativity and innovation.

8.7. The performance and recruitment of materials available in the design appropriately, in addition to achieving the aesthetic and plastic functionality in design.

8.8. Strengthen and activate the pros of the awareness of the ore and working on the development of contemporary plastic visions that derive their aesthetic from the art of stained glass.

8.9. Gaining experience in different techniques for glass arts, and the development of creative skills by experimentation and practice.

\section{Research Recommendations}

9.1. The interest to carry out studies linking the technical side and creative side applied in the program of stained glass art, to prepare the students for their high level of performance, efficiency and skill that must be available to the students level, and the perfection in the preparation period so that it can meet the demands of the teaching profession.

9.2. Strengthening the relationship between the Department of Art Education, at the Faculty of Education, Umm Al Qura University, and the Division of Interior Design at the Faculty of Arts and designs Umm Al Qura University, and glass factories, whether mechanical or civil Statistics, for the purpose of enriching the artistic process research and theoretical technology, which achieve the scientific and technical objective and help in the application of scientific and technical ideas in the process of glass formation in a scientific thoughtful.
9.3. The need to develop a stained glass course, by introducing new ideas and programs that help developing the creative side with the students, so the program comes out in a sophisticated framework and contributes to the supply of development projects by needs of professionals who are able to boost production towards the well-being and prosperity.

9.4. Dispatching students of the Department of Technical Education in intensive training courses for specific periods of modern and civil glass factories, to closely monitor and direct and clear the roads and the formation of the glass industry.

9.5. Paying attention to glass companies on the submitted researches in this area and taking them and using them, so as to improve the quality of their products and the emergence of distinctive products, which is reflected on the industry in general and technical industries in particular to enrich that field.

\section{References}

[1] Epstein Sam and Beryl, translation of: Abdel Fattah Al Menyawi, Glass, Dar el Maaref, Cairo, 1992.

[2] Abu Roraima - Hassan Raid, language arts, Dar Al Safaa for Publishing and Distribution, Amman, 2000.

[3] Pearson -Aj, Translation of : Amal Fadel Sarha, Reviewed by : Dr. Jawad Salman al-Badri, Glass Technology, Dar Al-Rasheed for publication, publications of the Ministry of Culture and Information the Republic of Iraq, a series of scientific books, number10, 1982.

[4] Hassan - Suleiman Mahmoud, The role of environmental materials in artistic composition, Journal of Studies and Research, University of Helwan, folder5, 1982, 39.

[5] Hammad - Ahmed Mohamed Abdul Nabil, Improving the physical and aesthetic properties of the glass surfaces using chemical drilling, Ph.D., Department of Industrial Designs, Glass Division, Faculty of Applied Arts, Helwan University, Cairo, 2002.

[6] Eldred-Cereal, Jewelries of Pharaohs, translation and investigation by: Mukhtar Al-Swaify, reviewed and presented by Dr. Ahmed Qadri, the first edition, Casablanca East, Cairo, 1990.

[7] Zinedine- Ali, Popular jewelries in Egypt, the Egyptian General Book Authority, Egypt, 1974.

[8] Mohammed Zenhom, The Art of Glass Technology, the thousand second book 166, the Egyptian General Book Authority, Cairo, 1995.

[9] Akel-Fakher, Education and creativity, Dar Al Ilm, Beirut, 1975.

[10] Abdul Aziz - Ezz Al-Din, Study of the techniques used on the glass by design and application and its relationship with contemporary architecture surfaces, Master Thesis, Department of Industrial Designs, Glass Division, Faculty of Applied Arts, Helwan University, Cairo, 1976.

[11] Awadallah- Mohamed Fathi, Ornamental metals, Dar Al-Maarefa [Eqraa series], Cairo, 1982.

[12] Ghorbal- Adel, The art of jewelry-making contemporary writings, Cairo, 1972.

[13] Ghoneima - Abdel FattahMustafa, The assets in search of Fine and Applied Arts, a series of cultural knowledge, Menoufia University Press, 2008.

[14] Ghoneima - Abdel Fattah, Industrial Chemistry for students of the arts and art education, a series of History of Science and Arts 4, Menoufia University Press, 2008.

[15] Muhammad- Ahmed Abdel Hady, The environmental dimension of development, Journal of Legal Research and Economic Faculty of Law, Cairo University, 1999.

[16] Al-Mahdi-Enayat, Metalworking and drafting, Dar Ibn Sina Cairo.

[17] Copper- Raouf, Glass Equipment Technology, Dar Al Nahda AlArabeya, Cairo, 1968.

[18] Copper- Hossam Eldin Farouq, Study of the scientific and technical foundations in the design and manufacture of glass products manually formed and its impact on raising production efficiency locally, Master Thesis, Department of Industrial Designs, Glass Division, Faculty of Applied Arts, Helwan University, 1995. 
[19] Copper - Mahmoud Mustafa, The industrial development of the glass and its impact on the mural paintings, $\mathrm{PhD}$ thesis, Painting Department, Faculty of Fine Arts, University of Alexandria, 2007.

[20] Andreade E.N. Tsient L.C., On Surface Crashes in Glasses, PracRoySoc.A., 1937, 159.

[21] Bates KennethThe Enamellist, A Comprehensive Study of Advanced Enameling Techniques, Cleveland, Ohio The World Publishing Company, 1967.

[22] Cohen, K., The art of Fine Enameling, Sterling Publishing Co., Inc. New York, 2004.

[23] Daremns, R. H., Fracture and Fatigue of Glass, j Mater. Sci. 15, 1982, 22.

[24] Evens, Chuck. Jewelry, Contemporary Design and Technique. Worcester, Massachusetts, Davis Publications, Inc, 1983.

[25] Fuller Moore, Concepts and Praclite, of Archliberal DayLighting, Van No Stand Renhaled, New York, 1997.

[26] Ross, Heather C., The Art of Bedouin Jewelry Saudi Arabian Profile, Switzerland: Arabesque Commercial SA, 1981.

[27] Joanna Gollberg, Making Metal Jewelry: Projects, Techniques, Inspiration, Lark Books Asheville NC, 2006.
[28] Judy Belcher and Steve Payne, Polymer Clay Creative Traditions, Watson-Guptill, N.Y, 2007.

[29] Sherri Haab, Metal Clay and Mixed Media Jewelry: Innovative Projects Featuring Resin, Polymer Clay, Fiber, Glass, Ceramics, Collage Materials, and More, Watson-Guptill: New York, 2007.

[30] Van Neumann Robert, The design and creation of Jewelry (3ed Ed.) Rdnor, Pennsylvania, 1982

[31] Pam East, Enameling on Metal Clay Watson-Guptill, New York, 2007.

[32] McMillan, D.Creative ways with Polymer Clay, Sterling Publishing Co., Inc.N. York, 2001.

[33] Fuller Moore, Concepts and Praclite, of Architeural Day Lighting, Van No Stand Renhaled, New York, 1997.

[34] W. Schiviecker, Glasterch, Ber 30, (1957).

[35] Magazine, Art Jewelry, Kalmbach Publishing Co. Waukesha, WI. USA.

[36] Magazine, American Craft Consul, New York, NY. USA.

[37] Jewelry Crafts Magazine, The Woodlands, TX. USA.

[38] Metalsmith Magazine, Soc of N American Goldsmiths, Ornament Magazine. Lark Books Asheville, NC. USA. 